\title{
Ivor Lewis Esophagectomy
}

National Cancer Institute

\section{Source}

National Cancer Institute. Ivor Lewis Esophagectomy. NCI Thesaurus. Code C140886.

A type of esophagectomy where an esophageal tumor is removed through an abdominal incision and a right thoracotomy. The esophagog astric anastomosis is located in the upper chest. 